\title{
Caracterização de concentrado proteico de feijão comum preto, cultivar Iapar 44, novo e envelhecido
}

\author{
Characterization of protein concentrates from new and aged dry black common beans, Iapar 44 cultivar
}

\author{
Horaci Jaqueline Silva de Souza RIBEIRO ${ }^{1}$, Sandra Helena PRUDENCIO ${ }^{2 *}$, \\ Dalva Tomoe MIYAGUI ${ }^{3}$, Edson Luis de Azambuja RIBEIRO ${ }^{4}$
}

\begin{abstract}
Resumo
Feijões endurecidos devido a condições impróprias de armazenamento têm sua qualidade e aceitabilidade afetadas. Para que sejam utilizados como produtos comestíveis, é necessário o estudo de processos tecnológicos que possibilitem seu aproveitamento. Portanto, este trabalho teve como objetivo caracterizar concentrados proteicos obtidos de feijão comum preto (Phaseolus vulgaris L.), cultivar Iapar 44, novo e envelhecido, bem como avaliar suas propriedades funcionais e sua utilização como ingrediente alimentar. O envelhecimento do feijão foi acelerado a $41{ }^{\circ} \mathrm{C}$ e $75 \%$ UR, por 30 e 60 dias, o feijão novo armazenado a $5{ }^{\circ} \mathrm{C}$ foi utilizado como controle. Concentrados proteicos foram obtidos por extração alcalina com $\mathrm{NaOH} 0,02 \%$ e posterior precipitação isoelétrica com $\mathrm{HCl}$ concentrado. Avaliaram-se o rendimento, composição química, perfil eletroforético das proteínas e propriedades funcionais de: solubilidade, absorção de água, formação de gel, absorção de óleo, capacidade e atividade emulsificante, estabilidade da emulsão, formação e estabilidade da espuma dos concentrados. O rendimento dos concentrados foi de $15 \%$ e estes apresentaram $75 \%$ de proteínas com perfil eletroforético e solubilidade proteica em água que variaram com o tempo de armazenamento. A solubilidade foi menor nos pHs 4 e 5. A absorção de água e a capacidade de formação de gel aumentaram com o armazenamento do feijão. A atividade emulsificante e estabilidade da emulsão foram prejudicadas pelo armazenamento de 60 dias. As demais propriedades não foram alteradas pelo armazenamento. Os resultados indicam possibilidades de uso do concentrado proteico de feijão armazenado como ingrediente alimentar.
\end{abstract}

Palavras-chave: aceitação; feijão duro; funcionalidade; ingrediente alimentar; Phaseolus vulgaris; proteínas.

\begin{abstract}
Hard beans, due to inappropriate storage conditions, have their quality and acceptability affected. In order to use them as edible products it is necessary to conduct studies on technological processes to make possible their utilization. Therefore, the objective of this work was to characterize protein concentrates obtained from new and aged dry black common beans (Phaseolus vulgaris L.), Iapar 44 cultivar, as well as to evaluate their functional properties and their usage as food ingredient. The aging of beans was accelerated by storage at $41{ }^{\circ} \mathrm{C}$ and $75 \% \mathrm{RH}$ for 30 and 60 days. The new sample, stored at $5{ }^{\circ} \mathrm{C}$, was taken as the control. Protein concentrates were obtained by alkaline extraction with $\mathrm{NaOH} 0,02 \%$ followed by isoelectric precipitation ( $\mathrm{pH} 4,5)$ with concentrated $\mathrm{HCl}$. The traits evaluated were: yield, chemical composition, eletrophoretic pattern of proteins, and the functional properties of solubility, water absorption, gel formation, oil absorption, emulsifying capacity, emulsifying activity, emulsion stability, foam formation, and foam stability. The protein concentrate average yield was $15 \%$ and the concentrates presented $75 \%$ of protein with eletrophoretic pattern of proteins and solubility in water that varied with the storage time. The protein solubility of the concentrate was affected by $\mathrm{pH}$, being lower at $\mathrm{pHs} 4$ and 5 . The functional properties of water absorption and gel formation increased with storage. The emulsifying activity and emulsion stability were affected by storage for 60 days. The other properties were not affected by storage. The results showed the possibility of using the protein concentrate from stored dry black beans as food ingredient. Keywords: acceptance; food ingredient; functionality; hard-bean; Phaseolus vulgaris; proteins.
\end{abstract}

\section{Introdução}

As leguminosas estão entre as mais importantes fontes alimentares do mundo, especialmente em países em desenvolvimento (REYES-MORENO; PAREDES-LÓPEZ, 1993). O feijão comum (Phaseolus vulgaris L.) é boa fonte de proteína (contém mais de $20 \%$ ) e energia (contém aproximadamente 60 a 70\% de carboidratos), além de conter minerais essenciais e vitaminas (SGARBIERI; ANTUNES; ALMEIDA, 1979). Entretanto, ao contrário dos cereais, os feijões podem deteriorar- se rapidamente em função do tempo e das condições de armazenamento e particularmente devido às altas temperaturas e umidades relativas, as quais são comuns em países tropicais como o Brasil (MARTÍN-CABREJAS et al., 1999).

O armazenamento prolongado do feijão e de outras leguminosas em condições de alta temperatura e umidade relativa tem sido associado com o desenvolvimento do defeito

Recebido para publicação em 21/11/2007

Aceito para publicação em 21/6/2009 (003027)

Programa Municipal de Alimentação Escolar - PMAE, Prefeitura Municipal de Rolândia - PMR, Av. Presidente Bernardes, 809, CP 83, CEP 86600-000, Rolândia - PR, Brasil, E-mail: hjaqueline12@hotmail.com

2 Departamento de Ciência e Tecnologia de Alimentos, Universidade Estadual de Londrina - UEL, CP 6001, CEP 86051-990, Londrina - PR, Brasil, E-mail: sandrah@uel.br

${ }^{3}$ Departamento de Bioquímica, Universidade Estadual de Londrina - UEL

${ }^{4}$ Departamento de Zootecnia, Universidade Estadual de Londrina - UEL

${ }^{*}$ A quem a correspondência deve ser enviada 
conhecido como hard-to-cook (HTC) ou "difícil de cozinhar" (JACKSON; VARRIANO-MARSTON, 1981; LIU et al., 1992; MARTÍN-CABREJAS et al., 1997; REYES-MORENO et al., 2000; YOUSIF et al., 2003; YOUSIF; KANO; DEETH, 2007).

Os mecanismos envolvidos no fenômeno HTC ainda não estão satisfatoriamente elucidados. As hipóteses mais importantes para explicar a causa do endurecimento são: a oxidação e/ou polimerização lipídica, formação de pectatos insolúveis, lignificação da lamela média, degradação $\beta$ eliminativa da pectina, desnaturação proteica, ligações cruzadas de proteínas desnaturadas e/ou polifenólicos e mecanismos múltiplos (REYS-MORENO; PAREDES-LÓPEZ, 1993; LIU, 1995; GARCIA et al., 1998).

O fenômeno HTC, ou seja, o endurecimento dos grãos de leguminosas afeta sua qualidade e aceitabilidade. Com o endurecimento aumenta o tempo de cocção dos grãos e, consequentemente, o gasto de energia, ocorrendo redução da palatabilidade e qualidade nutricional das leguminosas (REYSMORENO; PAREDES-LÓPEZ, 1993). Feijões endurecidos não formam um caldo espesso e viscoso, sendo que este é um importante parâmetro de qualidade para os consumidores de feijão na América Latina. Portanto, feijões endurecidos são menos aceitos pelos consumidores e causam importantes perdas (GARCIA; LAJOLO, 1994). Por isso, torna-se de grande importância tanto a prevenção do endurecimento como a utilização de grãos endurecidos (LIU, 1995).

Para a utilização dos grãos endurecidos é necessário o aprimoramento de processos tecnológicos que possam ser aplicados para a transformação de feijões endurecidos em produtos comestíveis. A utilização de alternativas tecnológicas como o descascamento, a maceração em soluções salinas, a fermentação, a extrusão e a produção de isolados e concentrados proteicos podem melhorar o valor nutricional e reduzir as perdas anuais dos feijões endurecidos (REYES-MORENO; PAREDES-LÓPEZ, 1993).

Sabe-se que farinhas e concentrados proteicos de algumas leguminosas têm pequena utilidade comercial devido a fatores que influenciam seu uso como o sabor, a textura, a presença de fatores de flatulência, fatores antinutricionais e sua funcionalidade (ENDRES, 1989). Alterações na funcionalidade de proteínas de leguminosas com defeito HTC podem ocorrer. (DONADEL; PRUDÊNCIO-FERREIRA, 1999; YOUSIF; KATO; DEETH, 2007; KAUR; SINGH, 2007). Assim, este trabalho teve como objetivo caracterizar concentrados proteicos obtidos de feijão comum preto, novo e envelhecido, bem como avaliar suas propriedades funcionais e sua utilização como ingrediente alimentar.

\section{Material e métodos}

\subsection{Matéria-prima}

O cultivar Iapar 44 de feijão comum (Phaseolus vulgaris L) preto foi cultivado na região de Mafra - Santa Catarina, sendo a colheita em fevereiro de 2002.

\subsection{Aceleração do envelhecimento dos grãos de feijão}

O feijão foi armazenado por 30 e 60 dias em duas estufas à temperatura de $41{ }^{\circ} \mathrm{C}$ e $75 \%$ de umidade relativa para acelerar o envelhecimento dos grãos (JACKSON; VARRIANOMARSTON, 1981). O feijão armazenado por 4 meses a $5{ }^{\circ} \mathrm{C}$ foi utilizado como controle. A umidade relativa de $75 \%$ foi obtida com um microclima de uma solução saturada de $\mathrm{NaCl}$ (RAO; RIZVI, 1986).

\subsection{Medida do tempo de cozimento dos grãos}

Determinou-se o tempo de cozimento dos grãos, após maceração em água por 18 horas em temperatura ambiente, utilizando-se equipamento de MATTSON adaptado com 25 cilindros calibrados. O tempo de cozimento foi tomado quando 13 cilindros penetraram nos grãos (JACKSON; VARRIANO-MARSTON, 1981).

\subsection{Preparo e rendimento do concentrado proteico}

A obtenção dos concentrados proteicos teve como base os trabalhos de Fan e Sosulski (1979) citados por Kohnhorst et al. (1991) e Donadel e Prudêncio-Ferreira (1999). Inicialmente obteve-se a farinha por meio da trituração dos grãos em moinho de facas marca Tecnal e posterior classificação em peneira com malha de $0,50 \mathrm{~mm}$. Os concentrados foram obtidos a partir da farinha, por extração alcalina com solução de $\mathrm{NaOH} 0,02 \%$. A farinha foi diluída em $\mathrm{NaOH}$ na proporção de 1:6 (peso:volume) e agitada em agitador de haste por 15 minutos e centrifugada a 5300 g por 10 minutos. O resíduo foi reextraído sob as mesmas condições. Os sobrenadantes foram tratados com $\mathrm{HCl}$ concentrado em pH 4,5 e centrifugados a 5300 g por 10 minutos. O precipitado foi ressuspendido em água destilada, o pH ajustado para 6,6 com $\mathrm{NaOH} 1 \mathrm{~N}$, e então seco em estufa com circulação de ar a $40{ }^{\circ} \mathrm{C}$. Após secagem os concentrados foram moídos, classificados em peneira de malha $0,59 \mathrm{~mm}$, acondicionados em sacos plásticos e mantidos sob refrigeração a $5{ }^{\circ} \mathrm{C}$ até a realização das análises.

O rendimento de cada concentrado foi calculado dividindose o peso do concentrado seco pelo peso da respectiva farinha, e multiplicado por 100 .

\subsection{Composição química}

Os teores de umidade, proteínas, lipídios e cinzas foram determinados, em triplicata, nos concentrados proteicos de feijão, seguindo os métodos padrões descritos pela AOAC (1990). Também nas farinhas dos feijões foi determinado o teor de proteína. O teor de carboidratos foi estimado por diferença.

\subsection{Eletroforese}

O procedimento descrito por Laemmli (1970) foi empregado para condução da eletroforese em SDS-PAGE. Foram utilizadas cuba vertical (modelo 250-TA 75, marca PHARMACIA) e fonte com voltagem e corrente controladas (modelo EPS 3500, marca PHARMACIA). 
Para a eletroforese foram preparados géis de $10 \times 6 \mathrm{~cm}$ utilizando-se poliacrilamida $12 \%$ (gel separador) e gel concentrador a $4 \%$. As amostras dos concentrados proteicos de feijão novo e armazenados foram solubilizadas no tampão da amostra, e $5 \mu \mathrm{L}$ da mistura contendo aproximadamente $40 \mu \mathrm{g}$ de proteínas foram aplicadas no gel. Um padrão de proteínas de peso molecular conhecido marca GIBCO BRL $10 \mathrm{kDa}$ Protein Ladder, $\mathrm{n}^{\circ}$ 10064-012, contendo proteínas de massa molecular de 10 a $120 \mathrm{kDa}$, com incrementos de 10 unidades e $200 \mathrm{kDa}$, também foi aplicado ao gel. A corrente elétrica empregada foi de $50 \mathrm{~V}$ até as proteínas migrarem para o gel separador e então a corrente foi aumentada para $100 \mathrm{~V}$. A revelação das bandas proteicas foi feita através da coloração rápida com prata, de acordo com o método apresentado por Henkeshoven e Dernick (1985).

\subsection{Propriedades funcionais}

Foram avaliadas as propriedades funcionais dos concentrados proteicos de feijão controle e de feijão armazenado nos diferentes tempos. Todas as determinações foram feitas em triplicata, exceto a propriedade de solubilidade que foi feita em duplicata.

\section{Solubilidade das proteinas}

A solubilidade da proteína em $\mathrm{pH}$ de 2 a 12 foi determinada de acordo com o método descrito por Okezie e Bello (1988). Um grama de amostra foi misturado em $50 \mathrm{~mL}$ de água destilada, ajustando-se o pH com $\mathrm{HCl} 1 \mathrm{~N}$ ou NaOH $1 \mathrm{~N}$, sob agitação. O material foi centrifugado a $5300 \mathrm{~g}$, por 20 minutos, e determinado o teor de proteína no sobrenadante.

A solubilidade das proteínas em água, sem ajuste do $\mathrm{pH}$, também foi determinada (LIU; McWATTERS; PHILLIPS, 1992).

A solubilidade da proteína foi calculada como: (massa de proteína no sobrenadante/massa de proteína na amostra) $\times 100$.

Os teores de proteína total e no sobrenadante foram determinados pelo método de Kjeldahl, utilizando-se o fator de conversão 6,25.

\section{Capacidade de absorção de água ou de óleo}

A capacidade de absorção de água ou de óleo foi determinada utilizando o método descrito por Okezie e Bello (1988). Uma suspensão com $50 \mathrm{~mL}$ de água ou óleo e $1 \mathrm{~g}$ de amostra foi preparada em tubos de centrífuga e agitada em agitador de tubos por 1 minuto. O material foi centrifugado a 5300 g por 20 minutos, desprezando-se o sobrenadante.

A diferença entre o peso da amostra antes e após a absorção de água ou óleo foi tomada como a quantidade de água ou de óleo absorvida. A medida da capacidade de absorção de água ou óleo foi calculada como: ( $\mathrm{g}$ de água ou óleo absorvido pela amostra/g de amostra) $\times 100$.

\section{Propriedades emulsificantes}

A capacidade emulsificante foi medida de acordo com o método de Beuchat (1977). Homogeneizaram-se $1 \mathrm{~g}$ de amostra em $50 \mathrm{~mL}$ de água destilada em agitador de haste a $8000 \mathrm{~g}$. Após 30 segundos em dispersão, foi adicionado óleo de soja à mistura por meio de uma bureta, numa vazão de $7 \mathrm{~mL} /$ minuto. O ponto de inversão de fase foi registrado pelo aumento da resistência elétrica da emulsão, utilizando-se um voltímetro. A capacidade emulsificante foi calculada como a quantidade de óleo emulsificado por grama de amostra.

A atividade emulsificante e estabilidade da emulsão foram determinadas de acordo com o método descrito por Yasumatsu et al. (1972). Preparou-se uma suspensão com $1 \mathrm{~g}$ de amostra em $10 \mathrm{~mL}$ de água destilada e $10 \mathrm{~mL}$ de óleo de soja, em béquer de $100 \mathrm{~mL}$. A suspensão foi emulsificada em agitador de haste por 1 minuto a $8000 \mathrm{~g}$. A emulsão foi dividida em tubos graduados de centrífuga de $12 \mathrm{~mL}$ e centrifugada a 2200 g por 5 minutos. A atividade emulsificante foi calculada como: (volume da camada emulsificada/volume total no tubo) $\times 100$.

Para determinação da estabilidade, a emulsão preparada conforme o procedimento descrito anteriormente e dividida em tubos graduados de centrífuga, foi então aquecida em banhomaria $\left(80^{\circ} \mathrm{C}\right)$ por 30 minutos e posteriormente resfriada com água corrente por 15 minutos. A emulsão foi centrifugada a 2200 g por 5 minutos. A estabilidade da emulsão foi expressa como: volume da camada emulsificada remanescente/ volume total da camada emulsificada no tubo x 100 .

\section{Propriedades espumantes}

A capacidade de formação de espuma foi determinada pelo método descrito por Coffmann e Garcia (1977). Uma suspensão de $2 \mathrm{~g}$ de amostra com $100 \mathrm{~mL}$ de água destilada foi preparada em um béquer de $250 \mathrm{~mL}$, agitada com agitador de haste por 5 minutos a $8000 \mathrm{~g}$. A dispersão foi transferida para uma proveta graduada de $250 \mathrm{~mL}$. A capacidade de formação de espuma foi expressa como a \% de aumento de volume baseando-se no volume inicial e após a formação de espuma.

A proveta contendo a espuma foi mantida à temperatura ambiente e, então, medida a estabilidade da espuma por meio da redução percentual do volume em intervalos de 30, 60, 90 e 120 minutos.

\section{Capacidade de formação de gel}

A formação de gel foi determinada conforme o método descrito por Coffmann e Garcia (1977). Tubos de ensaio contendo dispersões de amostra em água destilada foram aquecidos a $90{ }^{\circ} \mathrm{C}$ por 30 minutos, resfriados à temperatura ambiente e refrigeradas a $4{ }^{\circ} \mathrm{C}$ por 12 horas. As concentrações de amostras testadas foram 13,14, 15, 16 e $17 \mathrm{~g} / 100 \mathrm{~mL}$ de dispersão. $\mathrm{O}$ resultado foi expresso com base na formação de gel a partir da menor concentração da amostra. 
Teste para utilização do concentrado proteico como ingrediente alimentar

\section{Elaboração de "maionese"}

O concentrado proteico de feijão armazenado por 60 dias foi utilizado como agente emulsificante na elaboração de uma "maionese sabor azeitonas". Optou-se por utilizar este concentrado a fim de verificar a viabilidade de obtenção da maionese a partir da amostra mais velha de feijão, a que estaria subjetivamente nas piores condições de aproveitamento. Os ingredientes utilizados na elaboração da "maionese" foram: concentrado proteico 0,18 g; água 18,29 g; óleo de soja 73,17 g; azeitona preta 7,86 g; vinagre $0,37 \mathrm{~g}$ e sal 0,13 g.

Concentrado proteico e água foram homogeneizados em agitador de haste marca Heidolf Diax 600 a 8000 g. Após 30 segundos em dispersão, foi adicionado óleo de soja à mistura através de uma bureta numa vazão de $7 \mathrm{~mL} /$ minuto. Após o preparo da emulsão adicionou-se o vinagre, sal e azeitona triturada e misturou-se manualmente.

\section{Avaliação sensorial}

Trinta provadores não treinados avaliaram a aceitação da "maionese" utilizando uma escala hedônica de 9 pontos ( 9 = gostei muitíssimo; 1 = desgostei muitíssimo). Os provadores receberam a amostra espalhada sobre uma torrada e as instruções de como avaliar os atributos de aparência, odor, sabor, textura e aceitação global.

Para cada atributo, foram calculadas as porcentagens de aprovação (notas 6 a 9), indiferença (nota 5) e de rejeição (notas 1 a 4). A partir dos resultados de aceitação global também foi calculado o índice de aceitação conforme Monteiro (1984).

\subsection{Análise estatística}

O experimento foi conduzido conforme delineamento em blocos ao acaso. Os tratamentos foram os tempos de armazenamento ( 0,30 e 60 dias) e os blocos, as estufas. As variáveis estudadas, com exceção de solubilidade de proteínas e estabilidade de espuma, foram analisadas de acordo com o modelo estatístico (Equação 1):

$\mathrm{Y}_{\mathrm{ijk}}=\mu+\mathrm{T}_{\mathrm{i}}+\mathrm{E}_{\mathrm{j}}+\mathrm{e}_{\mathrm{ijk}}$

onde $\mathrm{Y}_{\mathrm{ijk}}$ é a observação $\mathrm{k}$ no tempo de armazenamento $i$, na estufa $j ; \mu$ é a média geral; $T_{i}$ é o efeito do tempo de armazenamento i, sendo $i=0,30$ e 60; $E_{j}$ é o efeito da estufa $j$, sendo $\mathrm{j}=1$ e $2 ; \mathrm{e}_{\mathrm{ijk}}$ é o erro experimental associado à observação $\mathrm{Y}_{\mathrm{ijk}}$.

Para as propriedades de solubilidade de proteínas e estabilidade de espuma foi utilizado um esquema de parcelas subdivididas, no qual o tempo de armazenamento foi a parcela, e o $\mathrm{pH}$ ou tempo de estabilidade foram as subparcelas. Neste caso o modelo estatístico utilizado foi (Equação 2):

$\mathrm{Y}_{\mathrm{ijkl}}=\mu+\mathrm{T}_{\mathrm{i}}+\mathrm{E}_{\mathrm{j}}+(\mathrm{TE})_{\mathrm{ij}}+\mathrm{P}_{\mathrm{k}}+(\mathrm{TP})_{\mathrm{ik}}+\mathrm{e}_{\mathrm{ijkl}}$ onde $\mathrm{Y}_{\mathrm{ijkl}}$ é a observação 1 no tempo de armazenamento i, na estufa j, no $\mathrm{pH}$ (ou tempo de estabilidade) $\mathrm{k}$; $\mu$ é a média geral; $\mathrm{T}_{\mathrm{i}}$ é o efeito do tempo de armazenamento $\mathrm{i}$, sendo $\mathrm{i}=0$, 30 e 60; E é o efeito da estufa $j$, sendo $j=1$ e 2; (TE) $)_{i j}$ é erro experimental associado à parcela; $\mathrm{P}_{\mathrm{k}}$ é o efeito do $\mathrm{pH}$ (ou tempo de estabilidade) $\mathrm{k}$, sendo $\mathrm{k}=2,3,4,5,6,7,8,9,10,11$ e 12 (ou 30, 60, 90 e 120); (TP) $)_{\text {ik }}$ é o efeito da interação entre o tempo de armazenamento i e o pH (ou tempo de estabilidade) k; $e_{i \mathrm{jkl}}$ é o erro experimental associado à observação $\mathrm{Y}_{\mathrm{ij \textrm {kl }}}$.

As diferenças entre médias foram comparadas pelo teste Tukey, em nível de 5\% de probabilidade. Nas análises em parcelas subdivididas, as diferenças entre médias foram testadas pelo teste "t". Foi utilizado o pacote estatístico SAS (1994).

\section{Resultados e discussão}

\subsection{Medida do tempo de cozimento dos grãos}

O armazenamento dos feijões em alta temperatura e umidade relativa induziu o endurecimento dos grãos, levando ao aumento no tempo de cozimento, que foi mais pronunciado no período mais longo de armazenamento (Tabela 1). Estando estes resultados de acordo com os encontrados por vários pesquisadores (GARCIA-VELA; STANLEY, 1989; HENTGES; WEAVER; NIELSEN, 1991; AGUILERA; RIVERA, 1992; DONADEL; PRUDÊNCIO-FERREIRA, 1999; MORI, 2001).

\subsection{Composição química e rendimento dos concentrados}

A concentração resultou em $220 \%$ de aumento nos teores de proteínas, tendo em vista que as farinhas originadas do feijão controle e dos armazenados tinham em média 23,96\% de proteína.

A composição química e o rendimento dos concentrados proteicos obtidos de feijão novo e armazenados encontramse na Tabela 2. Os rendimentos dos concentrados de feijões armazenados por 30 e 60 dias foram maiores $(p \leq 0,05)$ que o rendimento do controle. De modo geral os rendimentos foram semelhantes ao encontrado por Kohnhorst et al. (1991) que foi de $14 \%$, quando utilizou metodologia semelhante para obtenção de concentrado proteico de feijão 'navy'.

O concentrado proteico de feijão armazenado por 30 dias apresentou o maior teor de umidade, e aquele obtido aos 60 dias não diferiu do controle. Os teores de proteínas foram semelhantes nos três tratamentos, diferindo dos resultados observados por Donadel e Prudêncio-Ferreira (1999), que notaram diminuição

Tabela 1. Medida do tempo de cozimento dos grãos de feijão comum controle e armazenados a $41{ }^{\circ} \mathrm{C}$ e $75 \%$ UR.

\begin{tabular}{cc} 
Tempo de armazenamento & Tempo de cozimento (minutos) ${ }^{\star}$ \\
\hline Controle $^{* *}$ & $21,83^{\mathrm{c}} \pm 0,75$ \\
30 dias & $50,33^{\mathrm{b}} \pm 3,08$ \\
60 dias & $139,50^{\mathrm{a}} \pm 8,98$ \\
\hline
\end{tabular}

*Valores médios de duas repetições com três determinações cada uma \pm desvio padrão; $* *$ controle $=$ feijão novo armazenado a $5{ }^{\circ} \mathrm{C}$; médias acompanhadas por letras diferentes diferem significativamente $(\mathrm{p} \leq 0,05)$. 
Ribeiro et al.

Tabela 2. Composição química* e rendimento dos concentrados protéicos de feijão comum controle e armazenados a $41^{\circ} \mathrm{C}$ e $75 \%$ UR.

\begin{tabular}{|c|c|c|c|c|c|c|}
\hline $\begin{array}{c}\text { Tempo de } \\
\text { armazenamento }\end{array}$ & Umidade (\%) & $\begin{array}{l}\text { Proteínas }{ }^{* * *} \\
\text { (b.s.) }(\%)\end{array}$ & $\begin{array}{l}\text { Lipídeos } \\
\text { (b.s.) (\%) }\end{array}$ & $\begin{array}{l}\text { Cinzas } \\
\text { (b.s.) (\%) }\end{array}$ & $\begin{array}{c}\text { Carboidratos } \\
\text { (b.s.) }(\%)\end{array}$ & $\begin{array}{c}\text { Rendimento }{ }^{* * * *} \\
(\%)\end{array}$ \\
\hline 30 dias & $9,99^{\mathrm{a}} \pm 0,13$ & $77,84^{\mathrm{a}} \pm 2,82$ & $3,31^{a} \pm 0,25$ & $4,73^{a} \pm 0,23$ & $14,12^{\mathrm{a}} \pm 2,72$ & $15,84^{a} \pm 1,97$ \\
\hline
\end{tabular}

(b.s.) Base seca; ${ }^{*}$ valores médios de duas repetições com três determinações cada uma \pm desvio padrão; ${ }^{* *}$ controle $=$ feijão novo armazenado a $5{ }^{\circ} \mathrm{C}$; ${ }^{* * *}$ fator de conversão $=6,25$; ${ }_{* * * *}$ médias \pm desvio padrão; e médias na coluna, para amostra, acompanhadas por letras diferentes diferem significativamente $(\mathrm{p} \leq 0,05)$.

no teor de proteínas de concentrados proteicos de feijão carioca com o aumento do tempo de armazenamento a $41^{\circ} \mathrm{C}$.

O teor de lipídios diminuiu após 60 dias de armazenamento. $\mathrm{O}$ teor de cinzas e carboidratos manteve-se constante com o armazenamento.

\subsection{Eletroforese das proteínas}

Houve alterações no perfil eletroforético das proteínas dos concentrados proteicos obtidos após o armazenamento dos grãos, conforme demonstrado na Figura 1. Nota-se que proteínas de peso molecular mais baixo diminuíram ou se perderam, sendo que aos 30 dias as bandas se tornaram menos evidentes, porém retornando aos 60 dias de armazenamento, além do aparecimento de outras bandas de menor mobilidade. Isto é coerente com alguns resultados de medidas de propriedades funcionais obtidos neste trabalho, que após sofrerem redução aos 30 dias de armazenamento tiveram seus valores aumentados aos 60 dias. Os diferentes perfis eletroforéticos dos concentrados proteicos obtidos pelo mesmo processo, foram possivelmente causados porque os concentrados (controle, armazenado por 30 dias e armazenado por 60 dias) possuíam proteínas em diferentes estágios de desnaturação. Esses resultados concordam com Hussain, Watts e Bushuk (1989), que também observaram diferenças em feijão armazenado por nove meses a $15{ }^{\circ} \mathrm{C} / 35 \%$ UR e a $30{ }^{\circ} \mathrm{C} / 80 \%$ UR, sendo que nesta condição houve o aparecimento de novas bandas de menor mobilidade, que, segundo o autor, pode ter ocorrido devido à alguma associação e/ou desnaturação de proteínas durante o armazenamento. Berrios, Swanson e Cheong (1999) e Mori (2001) não encontraram diferenças no perfil eletroforético das frações proteicas de feijões armazenados.

Segundo Endres (1989), no processo de preparo de concentrados proteicos por precipitação isoelétrica as proteínas maiores são imobilizadas, tornando-se insolúveis, e há perda de proteínas solúveis. Isto justificaria o não aparecimento de proteínas de baixo peso molecular, pois, sendo mais solúveis ou até mesmo tendo ponto isoelétrico diferente de 4,5 , não teriam sido precipitadas.

Yousif et al. (2003) observaram pequena desestabilização de feijão 'adzuki' (Vigna angularis) que foram armazenados por seis meses a $30{ }^{\circ} \mathrm{C} / 65 \%$ UR, por meio de análise das proteínas por cromatografia líquida de alta eficiência e da medida da temperatura de desnaturação por calorimetria diferencial de varredura. Segundo os autores, a estabilidade das proteínas nas condições de armazenamento foi devido ao baixo conteúdo de lipídios no feijão 'adzuki'. O armazenamento, em condições

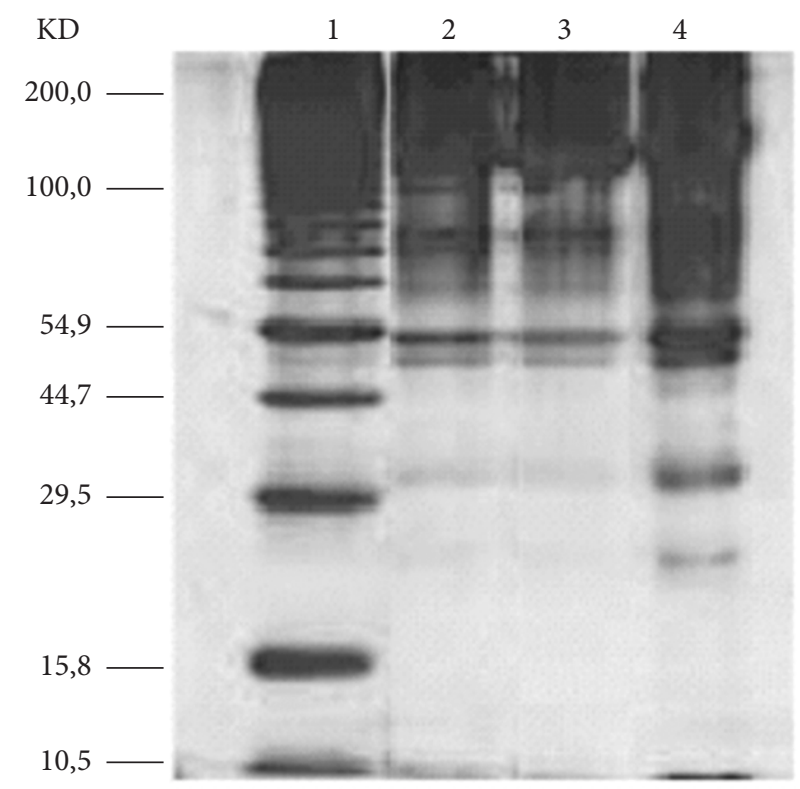

Figura 1. Eletroforese das frações proteicas dos concentrados de feijão comum, controle e armazenados a $40{ }^{\circ} \mathrm{C} / 75 \%$ UR $(1=$ padrão de peso molecular; 2 = concentrado de feijão controle (feijão novo armazenado a $5^{\circ} \mathrm{C}$ ); 3 = concentrado de feijão armazenado por 30 dias; $4=$ concentrado de feijão armazenado por 60 dias).

adversas de alta temperatura e umidade relativa, de feijões com conteúdo de lipídios mais elevado resulta na rancificação do lipídio e redução do $\mathrm{pH}$ do tecido do feijão e consequente alteração na estrutura molecular/desnaturação da proteína (LIU; McWATTERS; PHILLIPS, 1992).

\subsection{Solubilidade das proteínas e capacidade de absorção de água ou óleo}

Pela Figura 2 verifica-se que as menores solubilidades foram observadas nos pHs 4 e 5. Segundo Damodaran (1997), na maioria das proteínas ocorre mínima solubilidade no $\mathrm{pH}$ isoelétrico $(\mathrm{pH} 4-5)$, onde a repulsão eletrostática e a hidratação iônica são mínimas e a interação hidrofóbica entre as superfícies não polares é máxima. Resultados semelhantes foram encontrados em concentrado proteico de feijão fava novo e concentrados proteicos de feijão carioca novo e armazenado por Otegui et al. (1997) e Donadel e Prudêncio-Ferreira (1999).

As solubilidades das proteínas do concentrado obtido de feijão armazenado por 30 dias foram inferiores, na maioria dos $\mathrm{pHs}$, às solubilidades encontradas nos outros concentrados. 
Sendo que aos 60 dias, as solubilidades foram semelhantes às encontradas no concentrado controle (Figura 2).

Estes resultados foram confirmados pelos resultados das medidas de solubilidade em água das proteínas (Tabela 3), em que o concentrado proteico obtido aos 30 dias de armazenamento apresentou valor inferior aos demais, e o obtido aos 60 dias o maior valor. Apesar de se ter obtido concentrados com mesmo teor de proteínas (Tabela 2), os perfis eletroforéticos e solubilidade das proteínas foram diferentes (Figuras 1 e 2 e Tabela 3), indicando que foram extraídas frações proteicas diferentes e/ou em diferentes estágios de desnaturação de acordo com o tempo de armazenamento (SOSULSKI; KASIRYEALEMU; SUMNER, 1987; LIU; McWATTERS; PHILLIPS, 1992; DONADEL; PRUDÊNCIO-FERREIRA, 1999).

Houve aumento significativo da capacidade de absorção de água dos concentrados durante o armazenamento (Tabela 3). Chavan, McKenzie e Shahidi (2001) citam que a concentração de proteína e possivelmente as suas características conformacionais podem influenciar a capacidade de absorção de água. Durante o armazenamento pode ter havido alterações na estrutura das proteínas, expondo mais sítios para ligação com as moléculas de água.

Não houve diferença significativa na capacidade de absorção de óleo dos concentrados proteicos de feijão novo e armazenados (Tabela 3). Sosulski, Kasirye-Alemu e Sumner (1987) também não encontraram diferença nesta propriedade em concentrado proteico de feijão-fradinho novo e armazenado a 64 e 79\% UR obtido por extração alcalina. O mesmo resultado foi verificado

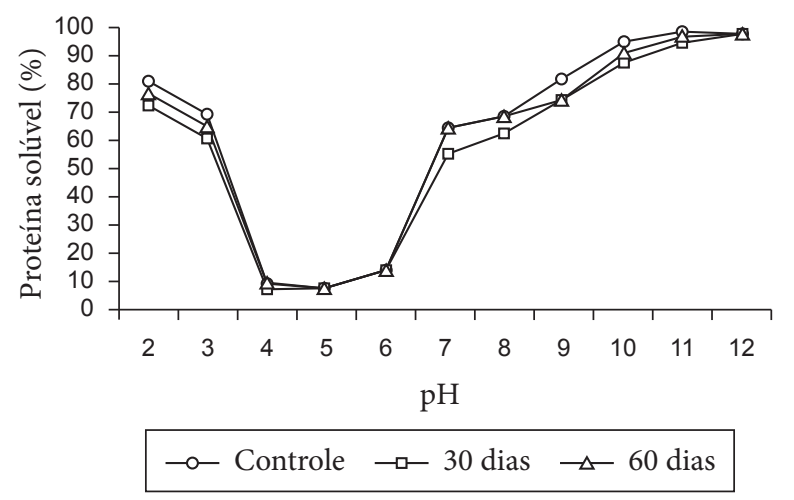

Figura 2. Curva de solubilidade dos concentrados proteicos de feijão comum controle e armazenados a $41^{\circ} \mathrm{C}$ e $75 \%$ UR. (controle $=$ feijão novo armazenado a $5^{\circ} \mathrm{C}$ ). por Donadel e Prudêncio-Ferreira (1999) em concentrado de feijões novo e armazenados a $41^{\circ} \mathrm{C}$ por 20 e 30 dias, porém no concentrado obtido aos 40 dias de armazenamento observaram aumento significativo na absorção de óleo.

\subsection{Capacidade de formação de gel}

Os resultados apresentados na Tabela 4 para capacidade de formação de gel demonstram que o concentrado de feijão novo formou gel somente na proporção de $15 \mathrm{~g}$ de amostra/100 mL de dispersão, e que os concentrados de feijões armazenados por 30 e 60 dias formaram gel na concentração de 14 e 15 g/100 mL. Os géis formados eram frágeis à agitação leve. A melhor capacidade de formação de gel apresentada pelos concentrados de feijões armazenados em relação ao controle pode ser devido à maior capacidade de absorção de água desses concentrados. Resultados semelhantes foram encontrados por Donadel e Prudêncio-Ferreira (1999) ao avaliarem as propriedades funcionais de concentrado proteico de feijão comum, variedade carioca, envelhecido. A concentração mínima de dispersão para formação de gel observada neste trabalho foi maior do que as encontradas na literatura para isolados e concentrados de feijão 'mung' (COFFMANN; GARCIA, 1977); tremoço (KING; AGUIRRE; PABLO, 1985) e feijão fava (OTEGUI et al., 1997), novos.

\subsection{Propriedades emulsificantes}

Conforme resultados apresentados na Tabela 5, a capacidade emulsificante dos concentrados proteicos não variou com o armazenamento do feijão. Donadel e PrudêncioFerreira (1999) observaram que concentrados proteicos de feijão carioca armazenado por 20,30 e 40 dias a $41^{\circ} \mathrm{C}$ apresentaram menor capacidade emulsificante do que o controle. No entanto, os concentrados possuíam concentração

Tabela 4. Capacidade de formação de gel dos concentrados protéicos de feijão comum controle e armazenados a $41{ }^{\circ} \mathrm{C}$ e $75 \%$ UR, em diferentes concentrações de amostra.

\begin{tabular}{cccc}
\hline $\begin{array}{c}\text { Concentração (g amostra/100 } \mathrm{mL} \\
\text { de dispersão) }\end{array}$ & \multicolumn{3}{c}{ Tempo de armazenamento } \\
\cline { 2 - 4 } & Controle $^{\star}$ & 30 dias & 60 dias \\
\hline 13 & - & - & - \\
14 & - & + & + \\
15 & + & + & + \\
16 & - & - & - \\
17 & - & - & - \\
\hline
\end{tabular}

${ }^{*}$ Controle $=$ feijão novo armazenado a $5^{\circ} \mathrm{C}$.

Tabela 3. Solubilidade em água ${ }^{\star}$ e capacidade de absorção de água e/ou óleo ${ }^{\star *}$ dos concentrados protéicos de feijão comum controle e armazenados a $41{ }^{\circ} \mathrm{C}$ e $75 \%$ UR.

\begin{tabular}{|c|c|c|c|}
\hline Tempo de armazenamento & $\begin{array}{l}\text { Solubilidade }^{* *} \text { (g de proteína } \\
\text { solúvel/100 g de amostra) }\end{array}$ & $\begin{array}{c}\text { Capacidade de absorção } \\
\text { de água }{ }^{* * *}\end{array}$ & $\begin{array}{c}\text { Capacidade de absorção } \\
\text { de óleo }\end{array}$ \\
\hline Controle $^{* * *}$ & $37,65^{\mathrm{b}} \pm 1,72$ & $127,13^{c} \pm 2,10$ & $82,24^{a} \pm 7,05$ \\
\hline 30 dias & $16,23^{c} \pm 5,28$ & $145,16^{\mathrm{b}} \pm 4,48$ & $81,93^{a} \pm 5,45$ \\
\hline 60 dias & $50,57^{a} \pm 8,39$ & $160,18^{a} \pm 6,89$ & $83,55^{\mathrm{a}} \pm 6,02$ \\
\hline
\end{tabular}

${ }^{*}$ Valores médios de duas repetições com duas determinações cada uma \pm desvio padrão; ${ }^{* *}$ valores médios de duas repetições com três determinações cada uma \pm desvio padrão;
${ }_{* * *}$ controle $=$ feijão novo armazenado a $5{ }^{\circ} \mathrm{C} ;{ }^{* * * *}$ resultados expressos em g de água ou óleo/100 g de amostra; e médias acompanhadas por letras diferentes diferem significativamente $(\mathrm{p} \leq 0,05)$. 
de proteína que diminuíam com o tempo de armazenamento. No presente trabalho, utilizando-se igual concentração de amostra $(2 \mathrm{~g} / 100 \mathrm{~mL})$ para a formação da emulsão pode-se observar que não houve diminuição na capacidade emulsificante com o armazenamento, isto ocorreu provavelmente porque as amostras dos três tratamentos possuíam mesma concentração de proteína.

A atividade emulsificante foi avaliada a partir de uma suspensão com $10 \mathrm{~g}$ de amostra/100 mL de água (Tabela 5). A atividade emulsificante dos concentrados proteicos armazenados por 30 e 60 dias foram menores que o valor encontrado no concentrado de feijão novo, o que indica que esta propriedade foi afetada negativamente pelo armazenamento.

Quanto à estabilidade da emulsão, não houve diferença significativa entre o concentrado obtido de feijão novo e armazenado por 30 dias, porém o concentrado de feijão armazenado por 60 dias apresentou valor significativamente inferior ao concentrado de feijão armazenado por 30 dias, mas não do concentrado controle. A diferença entre as estabilidades das emulsões dos tratamentos de 30 e 60 dias deve-se provavelmente ao filme proteico viscoelástico mais frágil formado na interface da emulsão preparada com concentrado de feijão envelhecido por 60 dias, e que pode ter como causa as diferenças na conformação das proteínas (DAMODARAN, 1996).

\subsection{Propriedades espumantes}

Não houve diferença significativa na capacidade de formação de espuma entre os concentrados proteicos avaliados, conforme resultados apresentados na Tabela 6 . O valor médio de $30 \%$ para

Tabela 5. Capacidade emulsificante (CE), atividade emulsificante (AE) e estabilidade da emulsão (EE) dos concentrados protéicos de feijão comum controle e armazenados a $41{ }^{\circ} \mathrm{C}$ e $75 \% \mathrm{UR}^{\star}$.

\begin{tabular}{cccc}
\hline $\begin{array}{c}\text { Tempo de } \\
\text { armazenamento }\end{array}$ & $\mathrm{CE}^{\star * *}$ & $\mathrm{AE}^{\star * * *}$ & $\mathrm{EE}^{\star * * * *}$ \\
\hline Controle & $186,21^{\mathrm{a}} \pm 41,60$ & $48,30^{\mathrm{a}} \pm 0,68$ & $50,26^{\mathrm{ab}} \pm 3,46$ \\
30 dias & $155,40^{\mathrm{a}} \pm 13,21$ & $44,94^{\mathrm{b}} \pm 1,97$ & $53,21^{\mathrm{a}} \pm 4,47$ \\
60 dias & $182,41^{\mathrm{a}} \pm 30,59$ & $44,78^{\mathrm{b}} \pm 2,56$ & $47,53^{\mathrm{b}} \pm 2,17$ \\
\hline
\end{tabular}

*Valores médios de duas repetições com três determinações cada uma \pm desvio padrão; ${ }^{* *}$ controle $=$ feijão novo armazenado a $5{ }^{\circ} \mathrm{C}$; ${ }^{* * *}$ resultados expressos em $\mathrm{mL}$ de óleo/g de amostra; ${ }^{* * *}$ os resultados foram expressos em $\%$ de volume emulsificado/volume total; ${ }^{* * * *}$ os resultados foram expressos em $\%$ de volume emulsificado remanescente/ volume emulsificado total; e médias, na coluna, acompanhadas por letras diferentes diferem significativamente $(\mathrm{p} \leq 0,05)$. capacidade de formação de espuma para os concentrados foi inferior aos valores encontrados na literatura para concentrados proteicos de tremoço, feijão fava e ervilhas 'field', feijão alado e grão-de-bico (SATHE; DESPHANDE; SALUNKHE, 1982; SOSULSKI; McCURDY, 1987; OKEZIE; BELLO, 1988; PAREDES-LÓPEZ; ORDONICA-FALOMIR; OLIVARESVÁQUEZ, 1991). Mas, foi superior aos valores encontrados para concentrado de feijão fava (OTEGUI et al., 1997) e concentrados proteicos de feijão carioca novo e armazenado (DONADEL; PRUDÊNCIO-FERREIRA, 1999).

Sosulski, Kasirye-Alemu e Sumner (1987) também verificaram maior capacidade espumante em concentrados de feijão-fradinho novo e armazenados, obtidos por extração alcalina. Entretanto, nesse caso o armazenamento afetou a capacidade de formação de espuma, pois houve diminuição nesta propriedade com o armazenamento. Resultados semelhantes foram encontrados por Donadel e PrudêncioFerreira (1999) em concentrados proteicos de feijão carioca após 30 dias de armazenamento a $41^{\circ} \mathrm{C}$.

Em relação ao tempo de armazenamento, não houve diferença na estabilidade de espuma entre concentrados de feijão novo e armazenados por 30 e 60 dias para todos os tempos de repouso (Tabela 6). Porém, em relação ao tempo de repouso (minutos) não houve diferença significativa no concentrado de feijão novo, mas aos 30 e 60 dias de armazenamento a redução da espuma foi significativamente maior aos 120 minutos do que aos 30 minutos, sendo que a redução aos 60 e 90 minutos não diferiu dos tempos 30 e 120 minutos.

O perfil eletroforético e resultados da avaliação de propriedades funcionais indicam que provavelmente os concentrados obtidos de feijão novo e armazenados por 30 e 60 dias possuíam diferentes frações de proteína devido às possíveis alterações de conformação molecular.

No envelhecimento de feijão preto comum das variedades Jamapa e 'kidney' por método químico com tampão acetato 0,1 M e pH 4,0, Morales-De Léon et al. (2007) e Kaur e Singh (2007) obtiveram farinhas e isolados proteicos com propriedades funcionais (absorção de água e óleo, propriedades emulsificantes, espumantes e de formação de gel) alteradas em relação às amostras não envelhecidas. A eletroforese de isolados proteicos do feijão comum preto demonstrou diminuição nas bandas de 14 e $26 \mathrm{kDa}$ correspondentes ao grupo da fito-hemaglutinina nas amostras endurecidas, indicando alguma perda ou modificação da proteína. As alterações na

Tabela 6. Capacidade de formação de espuma e estabilidade da espuma dos concentrados protéicos de feijão comum controle e armazenados a $41^{\circ} \mathrm{C}$ e $75 \% \mathrm{UR}^{*}$.

\begin{tabular}{cccccc}
\hline \multirow{2}{*}{$\begin{array}{c}\text { Tempo de } \\
\text { armazenamento (dias) }\end{array}$} & Capacidade de & \multicolumn{4}{c}{ Estabilidade da espuma (\% de redução de volume) } \\
\cline { 3 - 6 } & formação de espuma & \multicolumn{4}{c}{ Tempo de repouso (minutos) } \\
\cline { 3 - 6 } & & 30 & 60 & 90 & 120 \\
\hline Controle $^{* *}$ & $33,74^{\mathrm{a}} \pm 7,66$ & $39,63^{\mathrm{aA}} \pm 2,55$ & $41,44^{\mathrm{aA}} \pm 3,10$ & $42,07^{\mathrm{aA}} \pm 4,08$ & $42,54^{\mathrm{aA}} \pm 4,94$ \\
30 & $24,25^{\mathrm{a}} \pm 6,92$ & $39,98^{\mathrm{aB}} \pm 5,14$ & $41,55^{\mathrm{aAB}} \pm 5,48$ & $43,25^{\mathrm{aAB}} \pm 4,96$ & $44,18^{\mathrm{aA}} \pm 4,58$ \\
60 & $32,19^{\mathrm{a}} \pm 7,84$ & $46,44^{\mathrm{aB}} \pm 3,92$ & $48,53^{\mathrm{aAB}} \pm 3,01$ & $50,20^{\mathrm{aAB}} \pm 4,42$ & $50,61^{\mathrm{aA}} \pm 4,00$ \\
\hline
\end{tabular}

${ }^{*}$ Valores médios de duas repetições com três determinações cada uma \pm desvio padrão; ${ }^{* *}$ controle $=$ feijão novo armazenado a $5{ }^{\circ} \mathrm{C}$; ${ }^{* * *}$ resultados expressos como $\%$ de aumento de volume; médias, na coluna, acompanhadas por letras minúsculas iguais não diferem significativamente ( $\mathrm{p} \geq 0,05)$; e médias, na linha, acompanhadas por letras maiúsculas diferentes diferem significativamente $(\mathrm{p} \leq 0,05)$. 
funcionalidade e perfil eletroforético podem estar relacionadas a modificações na estrutura ou desnaturação da proteína causadas pela ação do agente utilizado para acelerar o endurecimento (Morales-De Léon et al., 2007).

\subsection{Utilização do concentrado proteico como ingrediente alimentar}

O concentrado proteico armazenado durante 60 dias foi utilizado como agente emulsificante na concentração de $1 \mathrm{~g} / 100 \mathrm{~mL}$ de água, para elaboração de uma "maionese sabor azeitonas", cuja aceitação foi avaliada por provadores não treinados (Figura 3).

Para os atributos aparência, odor, sabor, textura e aceitação global, as porcentagens de aprovação (notas 6 a 9) foram 46,66; 53,$33 ; 69,99 ; 43,33 ;$ e $56,57 \%$, respectivamente. Para os mesmos atributos as porcentagens de indiferença (nota 5 ) foram 6,67; 20,$00 ; 10,00 ; 16,67 ;$ e $16,67 \%$, respectivamente; e para rejeição (notas 1 a 4 ) foram 46,$67 ; 26,67 ; 20,00 ; 40,01$; e $26,67 \%$, respectivamente. $\mathrm{O}$ índice de aceitação calculado de acordo com Monteiro (1984) foi de 62,59\% que pode ser considerado regular.
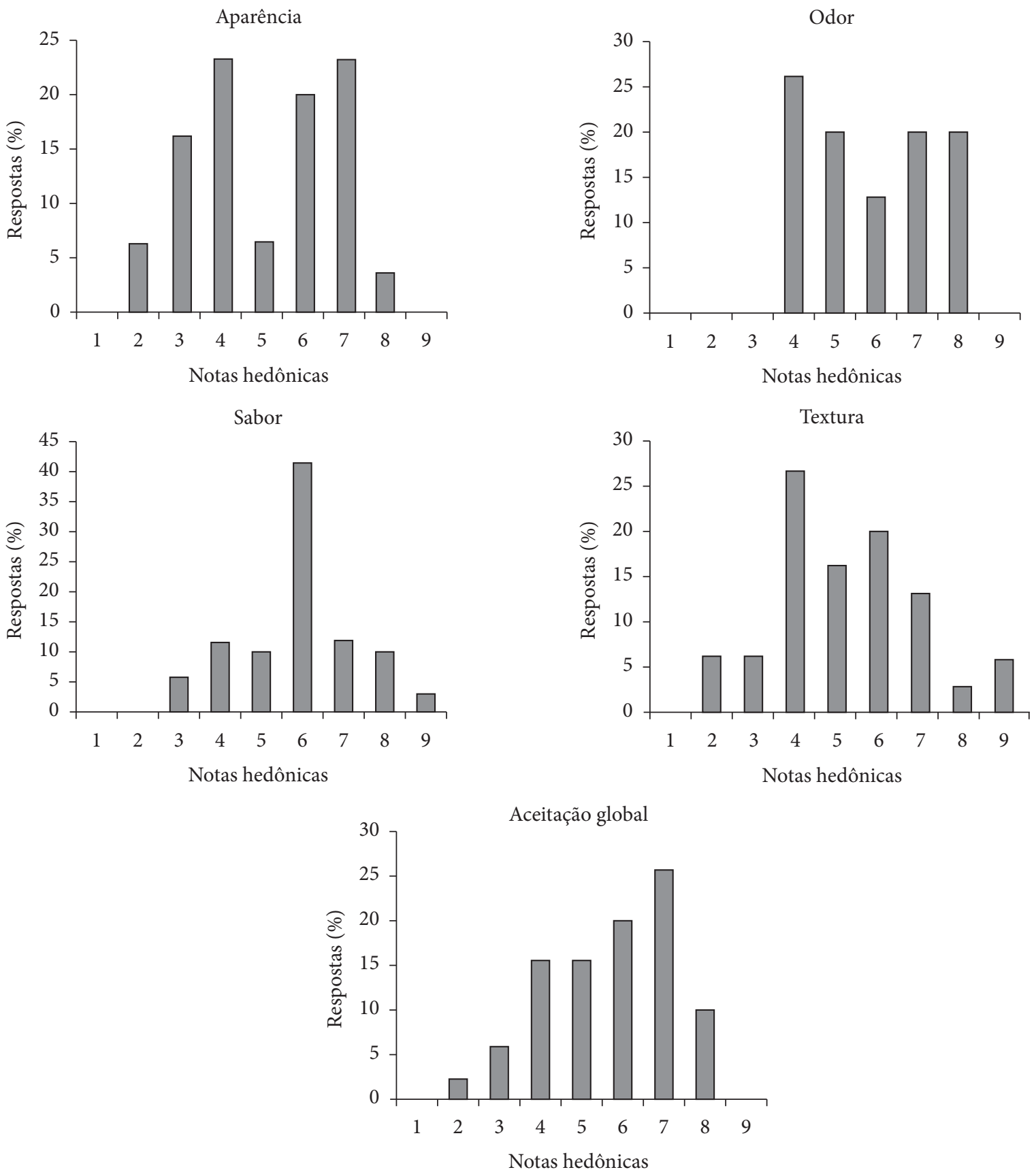

Figura 3. Distribuição das notas hedônicas para os atributos aparência, odor, textura e aceitação geral da "maionese sabor azeitona" elaborada com concentrado proteico de feijão armazenado por 60 dias a $41^{\circ} \mathrm{C}$ e $75 \%$ UR ( 1 = desgostei muitíssimo; $9=$ gostei muitíssimo). 
Pelos resultados obtidos, observou-se que o sabor apresentou a maior porcentagem de aprovação e a aparência e textura, as maiores porcentagens de rejeição. Assim, o concentrado de feijão pode ser utilizado como agente emulsificante na elaboração de maionese, porém para uma maior aceitação do produto há necessidade de melhorar a formulação do mesmo.

\section{Conclusões}

Os concentrados proteicos de feijões envelhecidos por diferentes tempos apresentaram teores de proteína semelhantes, porém suas estruturas moleculares foram alteradas. Da mesma forma, o envelhecimento afetou as propriedades funcionais dos concentrados. No entanto, os resultados obtidos indicam possibilidades de uso do concentrado proteico de feijão preto envelhecido como ingrediente alimentar.

\section{Referências bibliográficas}

AGUILERA, J. M.; RIVERA, R. Hard-to-cook defect in black beans: hardening rates, water imbibition and multiple mechanism hypothesis. Food Research International, v. 25, n. 2, p. 101-108, 1992.

Association of Official Analytical Chemists - AOAC. Offical methods of analysis. 15 ed. Washington, D. C., 1990.

BERRIOS, J. D. J.; SWANSON, B. G.; CHEONG, W. A. Physicochemical characterization of stored black beans (Phaseolus vulgaris

L.). Food Research International, v. 32, n. 10, p. 669-676, 1999.

BEUCHAT, L. R. Functional and eletrophoretic characteristics of succinylated peanut flour proteins. Journal of Agricultural and Food Chemistry, v. 25, n. 2, p. 258, 1977.

CHAVAN, U. D.; McKENZIE, D. B.; SHAHIDI, F. Functional properties of protein isolates from beach pea (Lathyrus maritimus L.). Food Chemistry, v. 74, n. 2, p. 177-187, 2001.

COFFMANN, C. N.; GARCIA, V. V. Functional properties and amino acid content of a protein isolate from mung bean flour. International Journal of Food Science and Technology, v. 12, n. 5, p. 473, 1977.

DAMODARAN, S. Amino acids, peptides, and proteins. In: FENNEMA, O. R. (Ed.). Food Chemistry. 3 ed. New York: Marcel Dekker, 1996. p. 321-428.

DAMODARAN, S. Food proteins: an overview. In: DAMODARAN, S.; PARAF, A. (Eds.). Food proteins and their applications. New York: Marcel Dekker, 1997. p. 1-24.

DONADEL, M. E.; PRUDENCIO-FERREIRA, S. H. Propriedades funcionais de concentrado protéico de feijão envelhecido. Ciência e Tecnologia de Alimentos, v. 19, n. 3, p. 380-386, 1999.

ENDRES, J. G. Legume protein flour and concentrates. In: MATTHEWS, R. H. (Ed.). Legumes: chemistry, technology, and human nutrition. New York: Marcel Dekker, 1989. p. 139-160.

GARCIA-VELA, L. A.; STANLEY, D. W. Protein denaturation and starch gelatinization in hard-to-cook beans. Journal of Food Science, v. 54, n. 5, p. 1284-1286, 1989.

GARCIA, E.; LAJOLO, F. M. Starch alterations in hard-to-cook beans (Phaseolus vulgaris). Journal of Agricultural and Food Chemistry, v. 42, n. 3, p. 612-615, 1994.

GARCIA, E. et al. Hard-to-cook beans (Phaseolus vulgaris): involvement of phenolic compounds and pectats. Journal of Agricultural and Food Chemistry, v. 46, n. 6, p. 2110-2116, 1998.
HENKESHOVEN, J.; DERNICK, R. Simplied method for silver staining of proteins in polyacrilamide gels and the mechanism of silver staining. Eletroforesis, n. 6, p. 103-112, 1985.

HENTGES, D. L.; WEAVER, C. M.; NIELSEN, S. S. Changes of selected physical and chemical components in the development of the hard-to-cook bean defect. Journal of Food Science, v. 56, n. 2, p. 436-442, 1991.

HUSSAIN, A.; WATTS, B. M.; BUSHUK, W. Hard-to-cook phenomenon in beans: changes in protein eletrophoretic patterns during storage. Journal of Food Science, v. 54, n. 5, p. 1367-1380, 1989.

JACKSON, G. M.; VARRIANO-MARSTON, E. M. Hard-to-cook phenomenon in beans: effects of accelerated storage on water absorption and cooking time. Journal of Food Science, v. 46, n. 3 , p. 799-803, 1981.

KAUR, M.; SINGH, N. A comparison between the properties of seed, starch, flour and protein separated from chemically hardened and normal kidney beans. Journal of the Science of Food and Agriculture, v. 87, n. 4. p. 729-737, 2007.

KING, J.; AGUIRRE, C.; PABLO, S. Functional properties of lupin protein isolates (Lupinus albus cv Multolupa). Journal of Food Science, v. 50, n. 1, p. 82-87, 1985.

KOHNHORST, A. L. et al. Production and characterization of a protein concentrate from navy beans (Phaseolus vulgaris). Food Chemistry, v. 41, n. 1, p. 33-42, 1991.

LAEMMLI, U. K. Cleavage of structural proteins during the assembly of the head of bacteriophage T 4. Nature, n. 227, p. 680-685, 1970.

LIU, K. et al. Hard-to-cook defect in cowpeas: Storage-induced and treatment-induced development. Journal of Food Science, v. 57, n. 5, p. 1155-1160, 1992.

LIU, K.; McWATTERS, K. H.; PHILLIPS, R. D. Protein insolubilization and termal destabilization during storage as related to hard-to-cook defect in cowpeas. Journal of Agricultural and Food Chemistry, v. 40, n. 12, p. 2483-2487, 1992.

LIU, K. Cellular, biological, and physicochemical basis for the hardto-cook defect in legume seeds. Critical Review in Food Science and Nutrition, v. 35, n. 4, p. 263-298, 1995.

MARTÍN-CABREJAS, M. A. et al. Changes in physicochemical properties of dry beans (Phaseolus vulgaris L.) during long-term storage. Journal of Agricultural and Food Chemistry, v. 45, n. 8, p. 3223-3227, 1997.

MARTÍN-CABREJAS, M. A. et al. Modifications to physicochemical and nutritional properties of hard-to cook (Phaseolus vulgaris L.) by extrusion cooking. Journal of Agricultural and Food Chemistry, v. 47, n. 3, p. 1174-1182, 1999.

MONTEIRO, C. L. B. Técnicas da avaliação sensorial. 2 ed. Curitiba: Universidade Federal do Paraná, CEPPA, 1984. 101 p.

MORALES-DE LÉON, J. C. et al. Preparation and characterization of protein isolate from fresh and hardened beans (Phaseolus vulgaris L.). Journal of Food Science, v. 72, n. 2, p. 96-102, 2007.

MORI, A. L. B. Solubilidade das proteínas de feijão comum envelhecido. Dissertação (Mestrado em Ciências de Alimentos) Universidade Estadual de Londrina - UEL, 2001. 78 p.

OKEZIE, B. O.; BELLO, A. B. Physicochemical and functional properties of Winged bean flour and isolate compared with soy isolate. Journal of Food Science, v. 53, n. 2, p. 450-454, 1988.

OTEGUI, I. et al. Properties of spray-dried and freeze-dried faba bean protein concentrates. International Journal of Food Science and Tecnology, v. 32, n. 6, p. 439-443, 1997. 
PAREDES-LÓPEZ, O.; ORDONICA-FALOMIR, C.; OLIVARESVÁQUEZ, M. R. Chickpea protein isolates: physicochemical, functional and nutritional characterization. Journal of Food Science, v. 56, n. 3, p. 726-729, 1991.

RAO, M. A.; RIZVI, S. S. H. Engeneering properties of foods. New York: Marcel Dekker, 1986. 398 p.

REYES-MORENO, C.; PAREDES-LÓPEZ, O. Hard-tocook phenomenon in common beans - A review. Critical Reviews in Food Science and Nutrition, v. 33, n. 3, p. 227-286, 1993.

REYES-MORENO, C. et al. Influence of storage at high temperature and high relative humidity on seed quality of chickpea (Cicer arietinum L.). Food Science and Technology International, v. 6, n. 6, p. 473-482, 2000.

SAS Institute. SAS User's Guide: Statistic. Cary: USA Inst., 1994.

SATHE, S. K.; DESPHANDE, S. S.; SALUNKHE, D. K. Functional properties of lupin seed (Lupinus mutabilis) proteins and protein concentrates. Journal of Food Science, v. 47, n. 2, p. 491-497, 1982.
SGARBIERI, V. C.; ANTUNES, P. L.; ALMEIDA, L. D. Nutritional evaluation of four varieties of dry beans (Phaseolus vulgaris L.). Journal of Food Science, v. 44, n. 5, p. 1306-1308, 1979.

SOSULSKI, F. W.; KASIRYE-ALEMU, E. N.; SUMNER, A. K. Microscopic, nutritional and functional properties of cowpea flours and concentrates during storage. Journal of Food Science, v. 52, n. 3, p. 700-706, 1987.

SOSULSKI, F. W.; McCURDY, A. R. Functionality of flours, protein fractions and isolates from field peas and faba bean. Journal of Food Science, v. 52, n. 4, p. 1010-1014, 1987.

YASUMATSU, K. et al. Whipping and emulsifing properties of soy bean products. Journal of Agriculture and Biology Chemistry, v. 36, n. 5, p. 719-727, 1972.

YOUSIF, A. M. et al. Effect of storage of adzuki bean (Vigna angularis) on starch and protein properties. Lebensmittel - Wissenschaft + Technologie, v. 36, n. 6, p. 601-607, 2003.

YOUSIF, A. M.; KATO, J.; DEETH, H. C. Effect of storage on biochemical structure and processing quality of adzuki bean (Vigna angularis). Food Reviews International, v. 23, n. 1, p. 1-33, 2007. 